\title{
Maximal response plateau to methacholine as a reliable index for reducing inhaled budesonide in moderate asthma
}

\author{
L. Prieto, V. Gutiérrez, C. Morales
}

\begin{abstract}
Maximal response plateau to methacholine as a reliable index for reducing inhaled budesonide in moderate asthma. L. Prieto, V. Gutiérrez, C. Morales. (C)ERS Journals Ltd 1999.

ABSTRACT: Although some studies suggest that asthma deteriorates after reducing inhaled steroids, results of long-term studies indicate that this might not be true for all patients. The aim of this study was to determine the utility of the detection of a plateau on the concentration-response curves to inhaled methacholine as a marker for safely reducing the dose of inhaled budesonide in asthmatic patients who are well-controlled with a moderately high dose of this inhaled steroid.

A total of 46 patients with moderate asthma, well-controlled for at least 6 months by treatment with $800 \mu \mathrm{g}$ budesonide daily, were included in the study. Subjects were treated for a 2-week run-in period with their usual dose of budesonide. At the end of the run-in, all subjects were challenged with methacholine $\left(0.095-200 \mathrm{mg} \cdot \mathrm{mL}^{-1}\right)$. Plateau responses, median effective concentration values, slopes and provocative concentration of methacholine causing a $20 \%$ fall in forced expiratory volume in one second (FEV1) values were measured. For the subsequent 12 weeks, patients were treated in an open design with budesonide at a reduced dose $(200 \mu \mathrm{g}$ once daily $)$, and were asked to record their peak expiratory flow (PEF) in the morning and in the evening. In addition, asthma symptoms and use of rescue terbutaline were recorded in diaries.

Plateaus were present in 24 patients, whereas 22 subjects showed concentrationresponse curves without evidence of a plateau. Ten patients in the nonplateau group deteriorated after reducing inhaled budesonide, compared to one patient in the plateau group $(\mathrm{p}=\mathbf{0 . 0 0 2})$. In the nonplateau group, FEV1 decreased from a baseline value of $3.28 \pm 0.19 \mathrm{~L}$ to $2.94 \pm 0.20 \mathrm{~L}$ at week $12(\mathrm{p}<0.0001)$. Likewise, morning PEF decreased from $419 \pm 19 \mathrm{~L} \cdot \mathrm{min}^{-1}$ at baseline to $394 \pm 19 \mathrm{~L} \cdot \mathrm{min}^{-1}$ at week $12(\mathrm{p}=0.02)$. By contrast, these variables remained unchanged in the plateau group.

In conclusion, in asthmatic patients, well-controlled with a moderately high dose of budesonide, the detection of a plateau on the concentration-response curve to inhaled methacholine may be used as a marker for safely reducing the corticosteroid dose. Eur Respir J 1999; 13: 1236-1244.
\end{abstract}

Sección de Alergología, Hospital Universitario Dr. Peset, Valencia, Spain.

Correspondence: L. Prieto

Sección de Alergología

Hospital Dr. Peset

C/ Gaspar Aguilar 90

46017 Valencia

Spain

Fax: 34963862501

Keywords: Airway hyperresponsiveness asthma

glucocorticosteroids

methacholine

plateau

Received: July 291998

Accepted after revision February 11999
Current therapy for asthma is aimed at suppressing the inflammatory process in the wall of the airways, thus reducing symptoms, bronchial hyperresponsiveness and airways obstruction. Inhaled corticosteroids are very effective in this respect and are considered the first-line treatment for patients with moderate-to-severe, persistent asthma [1]. Patient compliance can be a problem, since inhaled steroids do not have a direct symptom-relieving effect and sometimes have side-effects $[2,3]$. There is only limited data examining the delay between changes in inhaled steroid dosage and subsequent relapse, despite recent recommendations about the need for stepwise reductions in inhaled corticosteroid therapy as part of long-term management [1]. In practice, many physicians establish the optimum maintenance dose by initiating therapy at a high dose, which is then reduced once symptoms have been controlled [4]. Step-down rules are therefore required to prevent prolonged usage of high dosages of inhaled steroids in many patients $[5,6]$, but recent guidelines describe them rather vaguely [1]. The British Thoracic
Society guidelines [7] give some assistance by suggesting that reduction in inhaled steroids should be slow (every $1-3$ months by decreasing the dose by $\sim 25-50 \%$ at each step).

Although some studies suggest that asthma deteriorates after reducing inhaled steroids [8], results of long-term studies indicate that this might not be true for all patients $[9,10]$. In adults with asthma, JUNIPER et al. [9] found that after reducing inhaled steroids (given regularly during 1 yr), improvements in responsiveness and lung function could be maintained for at least 3 months. More recently, another study observed that the long-term remission during a 2-yr treatment period with high doses of budesonide was maintained for well over $1 \mathrm{yr}$ in patients treated with a dose that was reduced to one-third of the previous dosage [10]. Therefore, reducing the dose of an inhaled steroid might be possible in individual patients in a stable phase of the disease. However, what is needed is an objective measure to identify the subgroup of patients who do not deteriorate after reducing inhaled steroids. 
Airway hyperresponsiveness can be defined as the tendency of the airways to narrow too easily and too much in response to a wide variety of provoking stimuli [11]. Asthmatics differ from nonasthmatics in the position, slope and maximal response of the concentration-response curve to bronchoconstrictor stimuli, showing an increased sensitivity to inhaled stimuli, a steeper slope, and an increase in maximal constrictor response [12]. Thus, a maximal response plateau is a feature of nonasthmatic subjects [12-14], whereas it is very infrequently detected in subjects with mild asthma $[12,14]$. In moderate-tosevere asthmatics, a plateau in the constrictor response is usually not measurable, reflecting the potential for excessive airway narrowing [11]. Recently, Booms et al. [15] have shown that regular treatment with the inhaled corticosteroid budesonide introduces a plateau on the concentration-response curve to inhaled methacholine in most patients with asthma who initially exhibited unlimited obstruction. Furthermore, it was previously shown that in subjects with mild asthma, the absence of a plateau on the concentration-response curve to methacholine identifies those subjects with greater diurnal peak expiratory flow (PEF) variability [16].

The purpose of the current study was to evaluate the utility of the detection of plateau as a marker for safely reducing the dose of inhaled budesonide in patients wellcontrolled with a moderately high corticosteroid dose. The primary outcomes evaluated were the rates of severe and mild exacerbations of asthma. Secondary outcomes included lung function (forced expiratory volume in one second (FEV1) and PEF), symptoms, and the need for $\beta_{2}$-agonists as a rescue therapy.

\section{Subjects and methods}

\section{Subjects}

Male and nonpregnant female subjects 18-60 yrs of age with moderate bronchial asthma, well-controlled for at least 6 months by treatment with $800 \mu \mathrm{g}$ budesonide daily by Turbuhaler dry-powder inhaler (Astra, Barcelona, Spain) were recruited from the outpatient clinic. A diagnosis of asthma had been previously established by conventional criteria [17] which was confirmed either by demonstration of airway hyperresponsiveness to methacholine challenge (provocative concentration of methacholine causing a $20 \%$ fall in FEV1 $\left(\mathrm{PC}_{20}\right) \leq 8 \mathrm{mg} \cdot \mathrm{mL}^{-1}$ ) or a $>15 \%$ increase in FEV1 following inhaled salbutamol. All patients were nonsmokers. Subjects with only seasonal symptoms and skin sensitization to pollen allergens were excluded.

Inclusion and exclusion criteria were as follows: a clinical diagnosis of moderate bronchial asthma, which was well-controlled for at least 6 months by treatment with $800 \mu \mathrm{g}$ budesonide daily (i.e. symptoms $<2$ times per week, night-time symptoms $<2$ times per month, no emergency visits, no limitations on activities, including exercise); stable asthma during the run-in period (see below); regular use of budesonide Turbuhaler in a dosage of 400 $\mu \mathrm{g}$ twice daily for at least 10 months; no use of systemic glucocorticosteroids, anticholinergic agents, theophylline, disodium cromoglycate, nedocromil sodium, salmeterol or formoterol during the 6 months preceding the study; an FEV1 at initial screening $\geq 80 \%$ of predicted value and a ratio of $\mathrm{FEV} 1$ to $\mathrm{FVC} \geq 70 \%$; an ability to produce re- producible lung function tests, i.e., a variation in three consecutive measurements of FEV1 of $<5 \%$; no respiratory tract infections during the 4 weeks before the study; and no significant renal, hepatic or cardiovascular disease. The study protocol was approved by the Medical Ethics Committee of the author's hospital. Written informed consent was obtained from each subject prior to participation.

\section{Study design}

This open study lasted 14 weeks with a 2-week run-in period and a 12-week treatment period with budesonide at an unblinded reduced dose. The patients were seen at the outpatient clinic at the beginning and at the end of the runin period and after each 4 -week treatment period or in case of severe deterioration.

At the first visit, informed consent was obtained after full explanation, and a clinical assessment and spirometry were performed. Subjects were also instructed in the correct use of their peak flow meters and diary cards.

All study patients were treated for a 2-week run-in period with their usual dose of budesonide Turbuhaler (400 $\mu \mathrm{g}$ twice daily). Previous bronchodilator therapy was replaced with terbutaline sulphate administered through Turbuhaler (Terbasmin Turbuhaler, Astra), to be used only as needed for relief of acute symptoms; however, terbutaline had to be withheld for at least $6 \mathrm{~h}$ before the clinic visits. During the run-in period, subjects measured PEF in the morning and in the evening. In addition, asthma symptoms during the day and during the night, and use of rescue terbutaline were recorded in diaries. At the end of the run-in period, patients were eligible for study enrolment if they had stable asthma, defined as: no more than 2 days use of as-needed terbutaline; two or fewer mornings when PEF decreased $>20 \%$ from the previous evening PEF; two or fewer nights with awakenings caused by asthma requiring inhaled terbutaline; and $\mathrm{FEV} 1 \geq 80 \%$ pred and within $\pm 10 \%$ of the screening FEV1. These criteria were used to ensure that patients' conditions were stable with use of their current dose of budesonide. These eligible patients underwent high-concentration methacholine challenge and the follow-up visits were performed by personnel blinded to the results of the methacholine test.

For the next 12 weeks, eligible patients were treated with budesonide Turbuhaler at reduced dose $(200 \mu \mathrm{g}$ once daily). Terbutaline Turbuhaler as needed was permitted during the study. During the 2-week period prior to each follow-up visit, subjects recorded PEF twice daily, asthma symptoms during the day and during the night, and use of rescue terbutaline. Patients refrained from using rescue terbutaline for at least $6 \mathrm{~h}$ before clinic visits. New study drugs were dispensed at each visit. At each clinic visit, diary card information was assessed, and pulmonary function tests were performed to determine whether patients met predetermined asthma deterioration criteria. A mild exacerbation was defined when one of the following occurred on $\geq 5$ days: a fall in morning PEF $>20 \%$ compared with the average over the run-in period; diurnal variation in PEF $\geq 20 \%$; use of two or more inhalations of rescue terbutaline; and more than a one-step worsening in either day or night symptom score, compared with the average score during the run-in period rounded to the nearest integer (i.e. from 1 to 3 or from 0 to 2 , etc.). A severe exacerbation was defined as one requiring treatment with 
oral glucocorticoids, as judged by the investigator or a FEV $1 \leq 50 \%$ pred. Patients who had a severe exacerbation were withdrawn from the study and were placed on a regimen to restore asthma control. Methacholine responsiveness was also measured at study termination.

The amount of medication used was estimated by counting the number of unused doses of budesonide by turning the grip on the Turbuhaler until the red mark on the dose indicator was seen. The number of doses used was the total number of doses in the Turbuhaler minus the unused doses. Treatment compliance was reported as the actual number of doses used as a percentage of the expected number of doses.

\section{Methods}

Asthma symptoms and as-needed terbutaline requirements. Asthma symptoms were rated by the patient in the morning on arising and in the evening before retiring. Symptoms scores recorded in the morning indicate events from the previous night and information recorded in the evening refers to events during the day. The following scales were used for night-time symptoms: $0=$ none, $1=$ awoke once during the night or in the early morning because of symptoms, $2=$ awoke more than once during the night because of symptoms, $3=$ awake for a major part of the night because of symptoms, 4=awake for the whole night because of symptoms; and daytime symptoms: $0=$ none; $1=$ symptoms suffered once during a short period, $2=$ symptoms suffered for most of the day, but did not interfere with usual activities, $3=$ symptoms suffered for most of the day, interfering with usual activities, $4=$ very bad symptoms, could not go to work or do usual activities at all.

The number of night-time terbutaline inhalations for the preceding night was recorded in diary format in the morning on arising, and the number of daytime inhalations was recorded in the evening before retiring.

Skin prick tests. Skin-prick testing was performed with the 13 most common aeroallergens found in the Valencia area: house dust mites (Dermatophagoides pteronyssinus and D. farinae), household pets (cat and dog), pollens (mixed grass, olive, Parietaria judaica, Platanus orientalis, mixed weed), and moulds (alternaria, Aspergillus fumigatus, cladosporium and penicillium). Histamine and glycerinated saline were used as positive and negative controls. After $20 \mathrm{~min}$, weal size was recorded as the long axis and its perpendicular. A skin-test response was regarded as positive if the weal was $\geq 3 \mathrm{~mm}$ larger in diameter than that of the glycerinated saline.

Peak expiratory flow rate recording. PEF was measured in triplicate, in the morning on arising (morning PEF) and in the evening before retiring (evening PEF) and all three values were recorded. A Mini-Wright adult type peak flow meter (Clement Clarke International, London, UK) was used. Patients were instructed to measure PEF before using terbutaline as needed. Simple but detailed written instructions were supplied. All measurements were made with the subject in the upright posture.

Pulmonary function. Spirometry was carried out with a calibrated dry rolling seal spirometer (2130, Sensormed- ics Co., Yorba Linda, CA, USA). FEV1 and forced vital capacity (FVC) were measured [18] until three reproducible tracings, differing $<5 \%$ were obtained. Highest values were used for analyses. Reference values are those of the European Community for Coal and Steel [19].

High-concentration methacholine tests. Methacholine tests were performed using a tidal breathing method adapted from CockCROFT et al. [20] as described in detail previously [21]. Aerosols were delivered by a Hudson 1720 nebulizer (Temecula, CA, USA) with $2 \mathrm{~mL}$ of test solution in the container and $0.17 \pm 0.02 \mathrm{~mL} \cdot \mathrm{min}^{-1}$ delivery rate. All parts of the nebulizer were marked with waterproof paint to prevent interchanging. The nebulizer was connected directly to a mouthpiece, a nose clip was worn and the aerosol was inhaled through the mouth by tidal breathing for $2 \mathrm{~min}$. After inhalation of phosphatebuffered saline (PBS), subjects inhaled doubling concentrations of methacholine (Sigma Chemical, St. Louis, MO, USA) from 0.095 to $200 \mathrm{mg} \cdot \mathrm{mL}^{-1}$, diluted in PBS. A single determination of FEV1 was taken 60-90 s after inhalation of each concentration [22] unless the forced expiratory manoeuvre was judged to be technically unsatisfactory. The test was interrupted when FEV1 decreased by $>50 \%$ from its post-PBS value or when the highest concentration of methacholine had been administered. Two inhalations of salbutamol $(200 \mu \mathrm{g})$ from a metereddose inhaler were then administered to each subject, and the FEV1 was measured 15 min later. Further doses of salbutamol were given if necessary until the FEV1 returned to $>90 \%$ of the post-PBS value.

Data analysis. A sample size of 42 patients was calculated to provide $80 \%$ power to detect a difference of $35 \%$ in the proportion of subjects with deterioration of asthma between subjects with a plateau and patients without evidence of a plateau.

Concentration-response curves were plotted for each challenge test as percentage fall in FEV1 against the log methacholine concentration and were characterized by their sensitivity (PC20), slope and, if possible, by their position (median effective concentration (EC50)) and maximal response plateau level. Methacholine PC20 was calculated from the log concentration-response curves by linear interpolation of the two adjacent data points. Changes in $\mathrm{PC} 20$ were expressed in terms of doubling concentrations of methacholine calculated as $\Delta \log \mathrm{PC}_{20} /$ $\log 2$. A plateau response was considered to be present when, for three or more of the highest concentrations of methacholine, the FEV1 did not change by $>5 \%$. The level of the maximal FEV1 response was obtained by averaging the data points on the plateau [23]. Three subjects with a plateau during treatment with budesonide $800 \mu \mathrm{g} \cdot$ day $^{-1}$ lost the plateau at the end of treatment with a reduced dose. In these subjects, the plateau level values were assigned to per cent decline in FEV1 at the end of challenge. The position of the concentration-response curve in subjects with a plateau was assessed by EC50, which was obtained by interpolation. The slope of the linear portion of the concentration-response curve was calculated by linear regression analysis (using the method of least squares) of the data points $>5 \%$ fall in FEV 1 and all consecutive data points up to the first point of the plateau, or up to the last data point if no plateau was demonstrated. 
Table 1. - Baseline characteristics of the study patients

\begin{tabular}{|c|c|c|c|}
\hline & Plateau group & Nonplateau group & p-value \\
\hline Patients $n$ & 24 & 22 & \\
\hline Age yrs & $34.2 \pm 2.5$ & $31.1 \pm 2.7$ & 0.39 \\
\hline Male/female & $9 / 15$ & $6 / 16$ & 0.54 \\
\hline Duration of asthma yrs & $13.2 \pm 1.9$ & $16.9 \pm 1.6$ & 0.15 \\
\hline Duration of treatment months & $15.6 \pm 0.9$ & $15.8 \pm 1.0$ & 0.88 \\
\hline Atopy yes/no & $14 / 10$ & $18 / 4$ & 0.11 \\
\hline FEV1 \% pred & $101.7 \pm 2.6$ & $97.5 \pm 2.2$ & 0.23 \\
\hline FEV $1 /$ FVC $\%$ & $80.8 \pm 1.4$ & $79.4 \pm 1.3$ & 0.44 \\
\hline \multicolumn{4}{|l|}{ Run-in values } \\
\hline PEF morning $\mathrm{L} \cdot \mathrm{min}^{-1}$ & $426 \pm 22$ & $419 \pm 19$ & 0.80 \\
\hline PEF evenings $\mathrm{L} \cdot \mathrm{min}^{-1}$ & $433 \pm 24$ & $422 \pm 20$ & 0.74 \\
\hline Symptom scores total.week ${ }^{-1}$ * & $0.0(0.0-0.5)$ & $0.5(0.0-2.5)$ & 0.08 \\
\hline Terbutaline use doses $\cdot$ week $^{-1} *$ & $0.0(0.0-0.5)$ & $0.5(0.0-2.0)$ & 0.06 \\
\hline
\end{tabular}

Data are presented as means \pm SEM unless otherwise stated. PEF: peak expiratory flow; FEV1: forced expiratory volume in one second; FVC: forced vital capacity; *: data are median and quartile range.

Comparisons of the baseline characteristics of the two groups were performed by unpaired Student's t-tests for normally distributed continuous data, Mann-Whitney Utest for nonparametric continuous data and Fisher's exact test for categorical data.

The proportion of subjects with deterioration of asthma in each group was compared with the Fisher's exact test. The variables recorded in the diaries (the number of asthma symptoms, PEF, and the number of doses of supplemental $\beta_{2}$-agonist) were reduced to averages, and the averages for the run-in period were used as the reference value. For FEV1, the values measured at the end of the run-in period were used as the reference. Measurements of PEF, FEV1, slope and level of plateau are presented as means \pm SEM. All PC20 and EC50 values were log-transformed before analysis and presented as geometric means. Group differences were assessed using the Student's t-test. Symptom scores and the number of doses of terbutaline were expressed as medians and quartiles. All these data were analysed within groups by Wilcoxon's signed-rank test and between groups by the Mann-Whitney U-test. The analysis included all patients selected. Data for patients who withdrew were included up to the time of their withdrawal.

In a secondary analysis, various baseline measures were compared between subjects who deteriorated during the study and those who did not deteriorate. The Student's ttest was used for continuous measures and the Fisher's exact test was used for categorical data.

A two-sided $p$-value of $<0.05$ was considered to indicate statistical significance.

\section{Results}

Fifty subjects were initially selected, but data from only 46 subjects were analysed. Two subjects did not strictly fulfil entry criteria, one subject developed an upper respiratory infection during the run-in period, and one had unstable asthma.

In the initial evaluation, a maximal response plateau was detected in 24 patients (plateau group), whereas 22 subjects showed concentration-response curves without evidence of a plateau (nonplateau group). Baseline values (table 1) for age, sex, prevalence of atopy, time since diagnosis of asthma, duration of treatment with budesonide prior to entry, FEV1 ( $\%$ pred), morning PEF, and evening PEF were similar for the two groups. Symptom scores, and use of supplemental terbutaline were higher in the nonplateau group, although the differences were not significant. Compliance with the use of budesonide did not differ between the two groups $(81 \%$ in the plateau group and $74 \%$ in the nonplateau group, $\mathrm{p}=0.38$ ).

\section{Deterioration in asthma control}

Of the 46 subjects included, 43 completed the study. Three subjects of the nonplateau group were withdrawn because of a severe exacerbation of asthma, which was treated with a short course of oral steroids (one subject after 4 weeks and two subjects after 8 weeks of treatment with budesonide $200 \mu \mathrm{g} \cdot \mathrm{day}^{-1}$ ). Of the 22 patients in the nonplateau group, $10(45 \%)$ deteriorated after reducing inhaled budesonide, compared with one (4\%) patient in the plateau group. This difference was highly significant $(\mathrm{p}=0.002)$.

\section{Airway calibre}

The 4-weekly mean change from baseline in FEV1 over the course of the study is depicted in figure 1. In the

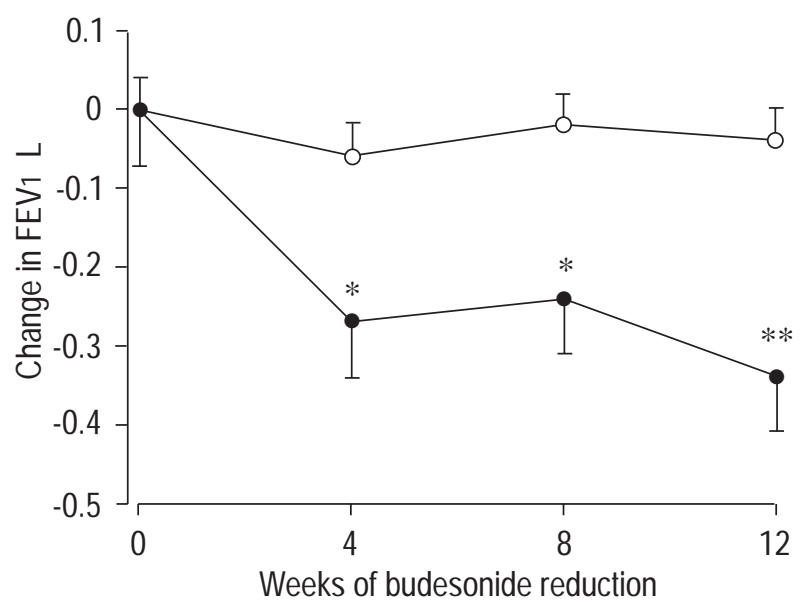

Fig. 1. - Forced expiratory volume in one second (FEV1) (mean \pm SEM) measured at clinic visits, expressed as changes from baseline. $\bigcirc$ : plateau group; $\bigcirc$ : nonplateau group. ${ }^{*}: \mathrm{p}<0.05 ;{ }^{*}: \mathrm{p}<0.01$. 
nonplateau group, the FEV1 decreased at all time points from a baseline value (mean \pm SEM) of $3.28 \pm 0.19 \mathrm{~L}$ to $3.01 \pm 0.18 \mathrm{~L}$ at week $4(\mathrm{p}=0.001), 3.04 \pm 0.21 \mathrm{~L}$ at week 8 $(\mathrm{p}=0.007)$, and $2.94 \pm 0.20 \mathrm{~L}$ at week $12(\mathrm{p}<0.0001)$. In the plateau group, the FEV1 values decreased from $3.24 \pm 0.15$ $\mathrm{L}$ at baseline to $3.18 \pm 0.14 \mathrm{~L}$ at week $4(\mathrm{p}=0.41), 3.22 \pm$ $0.16 \mathrm{~L}$ at week $8(\mathrm{p}=0.45)$, and $3.20 \pm 0.14 \mathrm{~L}$ at week 12 $(\mathrm{p}=0.43)$. The change in FEV1 from baseline was consistently larger in the nonplateau group than in the plateau group, the mean difference in the change between the groups being $0.21 \mathrm{~L}$ (95\% confidence interval (CI) $0.05-$ $0.37, \mathrm{p}=0.014)$ at week $4,0.22 \mathrm{~L}(95 \%$ CI $0.03-0.40$, $\mathrm{p}=0.02)$ at week 8 , and $0.30 \mathrm{~L}(95 \%$ CI $0.11-0.48, \mathrm{p}=$ 0.003 ) at week 12.

Figure 2 shows the changes in the mean values compared with the run-in period for morning and evening PEF. There were decreases in mean PEF recorded in the morning in both groups (table 2). However, these changes did not reach significance at any time point in the plateau group. In subjects without a plateau the worsening was significant at all time points. The difference between the two groups was significant at weeks 4 (mean $23 \mathrm{~L} \cdot \mathrm{min}^{-1}$; 95\% CI 7-39; p=0.006) and 12 (mean $28 \mathrm{~L} \cdot \mathrm{min}^{-1} ; 95 \%$ CI 2-54; $\mathrm{p}=0.038)$, but not at week 8 (mean $13 \mathrm{~L} \cdot \mathrm{min}^{-1}$; $95 \%$ CI $-11-37 ; \mathrm{p}=0.28$ ).

In both groups, the changes in evening PEF were not significant (table 2). Furthermore, these changes were not significantly different between the two groups.
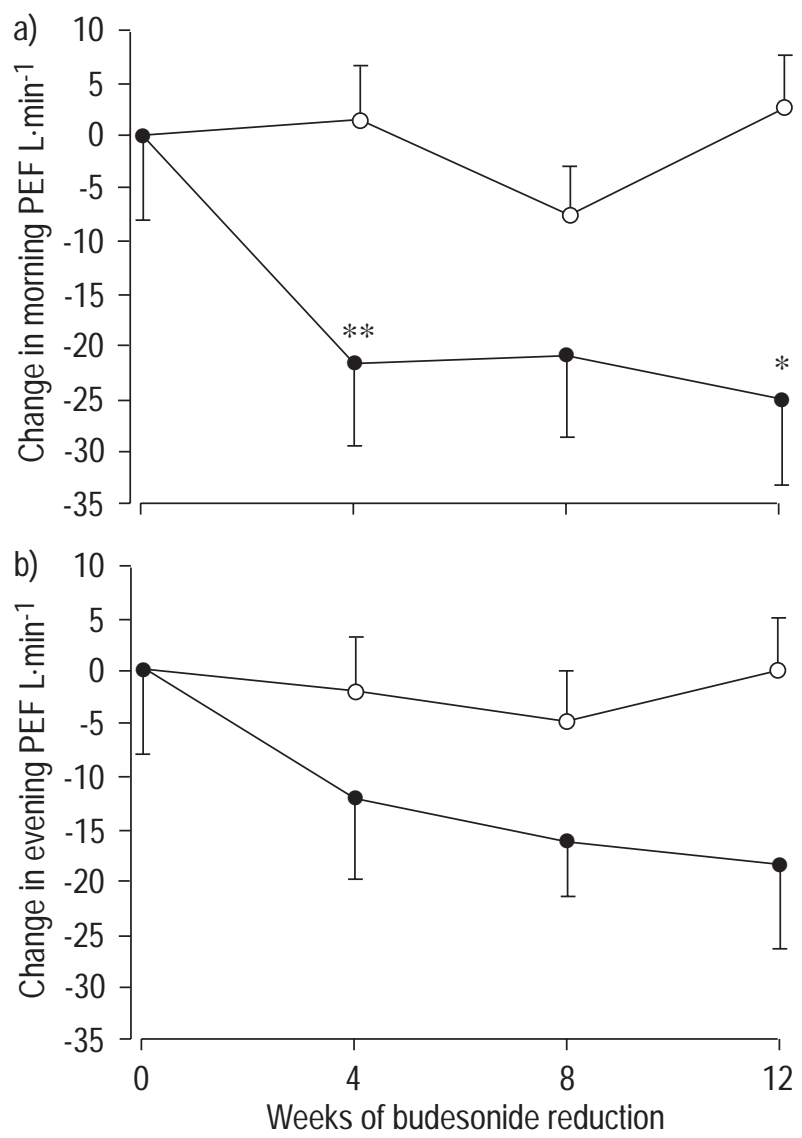

Fig. 2. - Mean \pm SEM change from baseline in morning (a) and evening (b) peak expiratory flow (PEF). $\bigcirc$ : plateau group; $\bigcirc$ : nonplateau group. *: $\mathrm{p}<0.05 ; * *: \mathrm{p}<0.01$.
Table 2. - Changes in peak expiratory flow (PEF; L. $\mathrm{min}^{-1}$ )

\begin{tabular}{lcccc}
\hline & Run in & Week 4 & Week 8 & Week 12 \\
\hline Plateau group & & & & \\
Morning PEF & $426 \pm 22$ & $425 \pm 23$ & $419 \pm 22$ & $426 \pm 21$ \\
p-value & & 0.78 & 0.43 & 0.87 \\
Evening PEF & $433 \pm 24$ & $431 \pm 23$ & $429 \pm 22$ & $433 \pm 22$ \\
p-value & & 0.82 & 0.78 & 0.87 \\
Nonplateau group & & & & \\
Morning PEF & $419 \pm 19$ & $397 \pm 18$ & $398 \pm 20$ & $394 \pm 19$ \\
p-value & & 0.003 & 0.021 & 0.02 \\
Evening PEF & $422 \pm 20$ & $410 \pm 18$ & $406 \pm 21$ & $404 \pm 20$ \\
p-value & & 0.08 & 0.07 & 0.10 \\
\hline
\end{tabular}

Values are means \pm SEM; $p$-values are for the comparison with baseline values within groups.

\section{Clinical signs}

At the end of the run-in period, when patients received $400 \mu \mathrm{g}$ budesonide twice a day, symptom scores and the rate of use of rescue terbutaline were low in both groups (table 1). When budesonide was reduced, patients in both groups had a slight increase in symptoms and use of terbutaline (fig. 3). These changes did not reach significance at any time point in the plateau group, but patients without a plateau reported increments in the severity of symptoms and in the use of terbutaline at week $4(p=0.04$
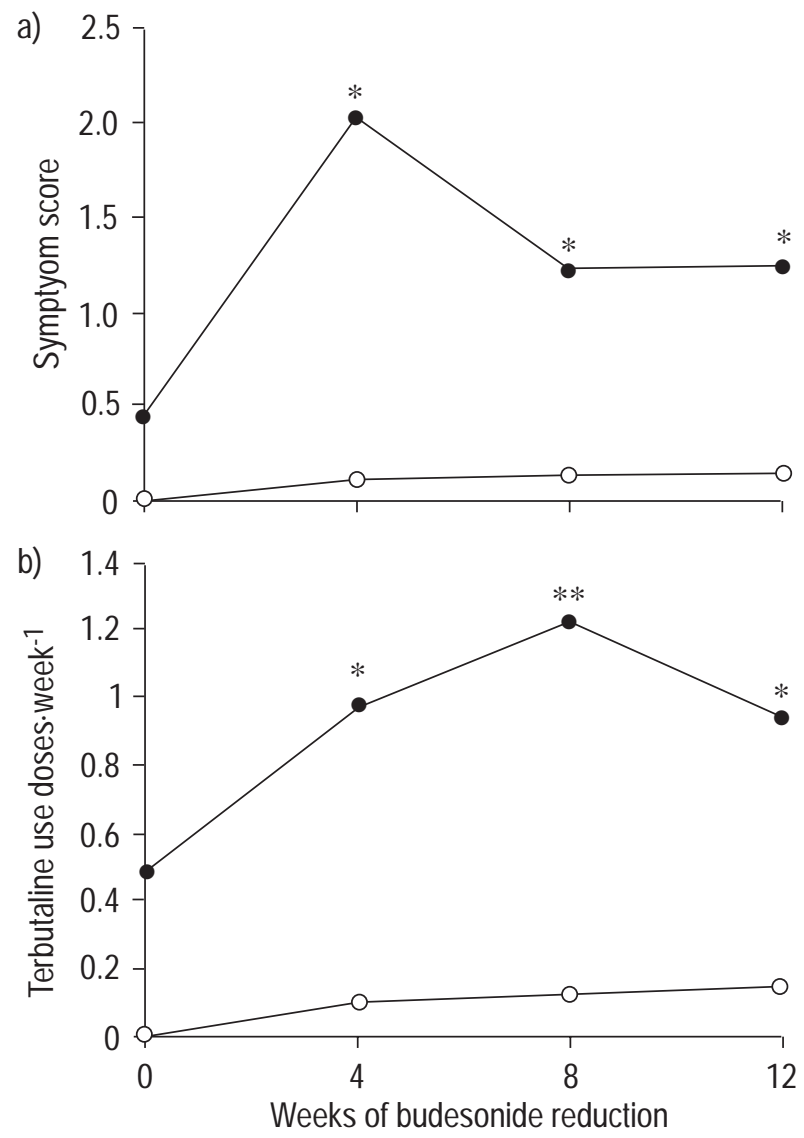

Fig. 3. - Median total weekly symptom scores (a) and $\beta$-agonist inhaler use (b) in subjects with a plateau $(\bigcirc)$ and patients without a plateau $(\bigcirc)$. *: $\mathrm{p}<0.05 ;{ }^{* *}: \mathrm{p}<0.01$, significantly different from baseline values. The difference between both groups is not significant. 


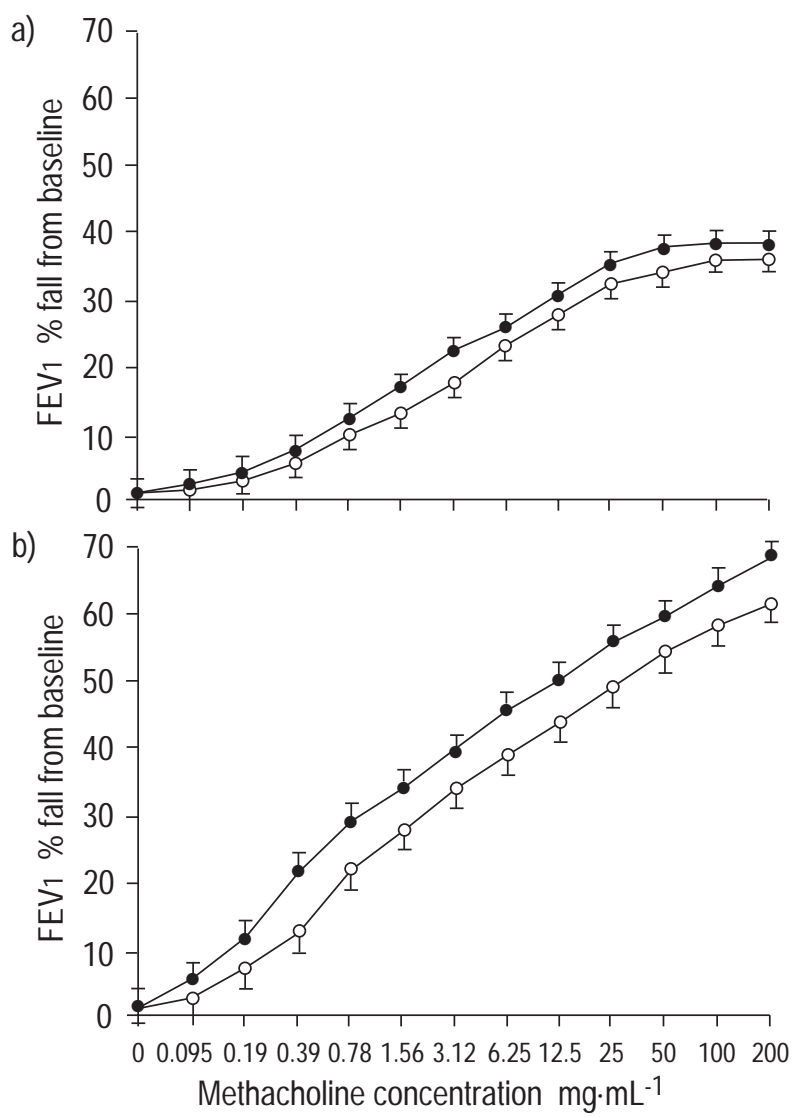

Fig. 4. - Mean \pm SEM concentration-response curves to inhaled methacholine in subjects with a plateau (a) and in those without a plateau (b) at baseline $(O)$ and at the end of follow-up $(\bigcirc)$. FEV1: forced expiratory voume in one second.

for both symptoms and terbutaline use), week 8 ( $\mathrm{p}=0.04$ for symptoms and $\mathrm{p}=0.006$ for terbutaline use), and week 12 ( $\mathrm{p}=0.04$ for symptoms and $\mathrm{p}=0.03$ for terbutaline use). The change from baseline was not significantly different between the two groups at any time point $(\mathrm{p}=0.54$ for severity of symptoms and $\mathrm{p}=0.52$ for terbutaline use).

\section{Airway hyperresponsiveness}

Since, in the absence of a plateau, PC20 and slope can be measured, subjects with and without a plateau were compared using these variables. The geometric mean (range) PC20 value for subjects with plateau was $5.5 \mathrm{mg} \cdot \mathrm{mL}^{-1}$ (0.7-198.0), compared with $1.4 \mathrm{mg} \cdot \mathrm{mL}^{-1}(0.1-19.0)$ in sub- jects without plateau $(\mathrm{p}<0.0001)$. There was also a significant difference in the slope (mean \pm SEM) between subjects who had a plateau $(15.1 \pm 1.3$ fall in FEV1 (\%)/log methacholine concentration $\left.\left(\mathrm{mg} \cdot \mathrm{mL}^{-1}\right)\right)$ and those who did not $(32.7 \pm 4.3$ fall in FEV1 (\%)/log methacholine concentration $\left.\left(\mathrm{mg} \cdot \mathrm{mL}^{-1}\right), \mathrm{p}<0.0001\right)$.

Figure 4 shows the mean concentration-response curves for both groups at baseline and at the end of the follow-up period. Both in the plateau group and in the nonplateau group, there were no significant modifications in slope (table 3 ). In addition, for the plateau group, there were no significant modifications in PC20, EC50 and the level of the plateau. However, the geometric mean (range) methacholine PC20 values decreased in the nonplateau group, from $1.4 \mathrm{mg} \cdot \mathrm{mL}^{-1}(0.1-19.0)$ during the initial assessment to $0.5 \mathrm{mg} \cdot \mathrm{mL}^{-1}(0.1-2.3, \mathrm{p}=0.008)$ at the end of follow-up (fig. 5). The average reduction was (mean \pm SEM) $-1.1 \pm 0.4$ doubling concentrations. Changes in PC20 were not significantly different between plateau and nonplateau groups, the mean difference being 0.65 (95\% CI $-0.44-1.75)$ doubling concentrations $(p=0.24)$.

In 35 patients there were no changes in any measure of asthma control during the treatment with a reduced dose of budesonide. These patients did not differ in age, sex, disease duration, treatment period with budesonide 800 $\mu \mathrm{g} \cdot \mathrm{day}^{-1}$, pulmonary function or methacholine responsiveness (PC20 and slope) from those whose asthma relapsed $(\mathrm{n}=11)$ after budesonide reduction (table 4$)$.

\section{Discussion}

In subjects with moderate asthma, well-controlled by treatment with $800 \mu \mathrm{g}$ budesonide daily, differences in the shape of the concentration-response curve to inhaled methacholine have been shown. Some patients exhibit plateaus, whereas in other subjects increasing doses of methacholine led to progressive airway narrowing without the evidence of a plateau response. In subjects with a plateau, no evidence of deterioration in the control of asthma (FEV1, PEF, airway responsiveness, symptoms, terbutaline use) was found over the course of 3 months when the dose of budesonide was reduced by $75 \%$. On the contrary, a deterioration in all clinical and functional variables was observed in patients without a plateau after the dose of budesonide was reduced. The number of subjects with unacceptable asthma control after reduction of inhaled budesonide was also higher in the nonplateau group. These results suggest that, for patients with stabilized moderate asthma who are relatively free of symptoms while receiving $400 \mu \mathrm{g}$ of budesonide twice daily, the detection of

Table 3. - Methacholine responsiveness in subjects with and without a plateau

\begin{tabular}{|c|c|c|c|c|}
\hline & \multicolumn{2}{|c|}{ Plateau group } & \multicolumn{2}{|c|}{ Nonplateau group } \\
\hline & Baseline & End of follow-up & Baseline & End of follow-up \\
\hline $\mathrm{PC} 20 \mathrm{mg} \cdot \mathrm{mL}^{-1 *}$ & $5.5(0.7-198.0)$ & $4.0(0.3-189.3)$ & $1.4(0.1-19.0)$ & $0.5(0.1-2.3)$ \\
\hline EC50 $\mathrm{mg} \cdot \mathrm{mL}^{-1} *$ & $2.9(0.7-8.3)$ & $2.4(0.6-6.8)$ & - & - \\
\hline $\begin{array}{l}\text { Slope fall in FEV1 }(\%) / \log \\
\text { methacholine concentration }\left(\mathrm{mg} \cdot \mathrm{mL}^{-1}\right) \\
\text { Level of plateau } \% \text { fall FEV1 }\end{array}$ & $\begin{array}{l}15.1 \pm 1.3 \\
34.8 \pm 1.9\end{array}$ & $\begin{array}{l}15.6 \pm 1.6 \\
37.6 \pm 2.5\end{array}$ & $\begin{array}{c}33.7 \pm 4.3 \\
-\end{array}$ & $\begin{array}{c}35.6 \pm 3.2 \\
-\end{array}$ \\
\hline
\end{tabular}

Data presented as means \pm SEM or geometric mean with range in parentheses. End of follow-up: end of the 3-month study period; PC20: provocative concentration of methacholine causing a $20 \%$ fall in forced expiratory volume (FEV1); EC50: median effective concentration. 

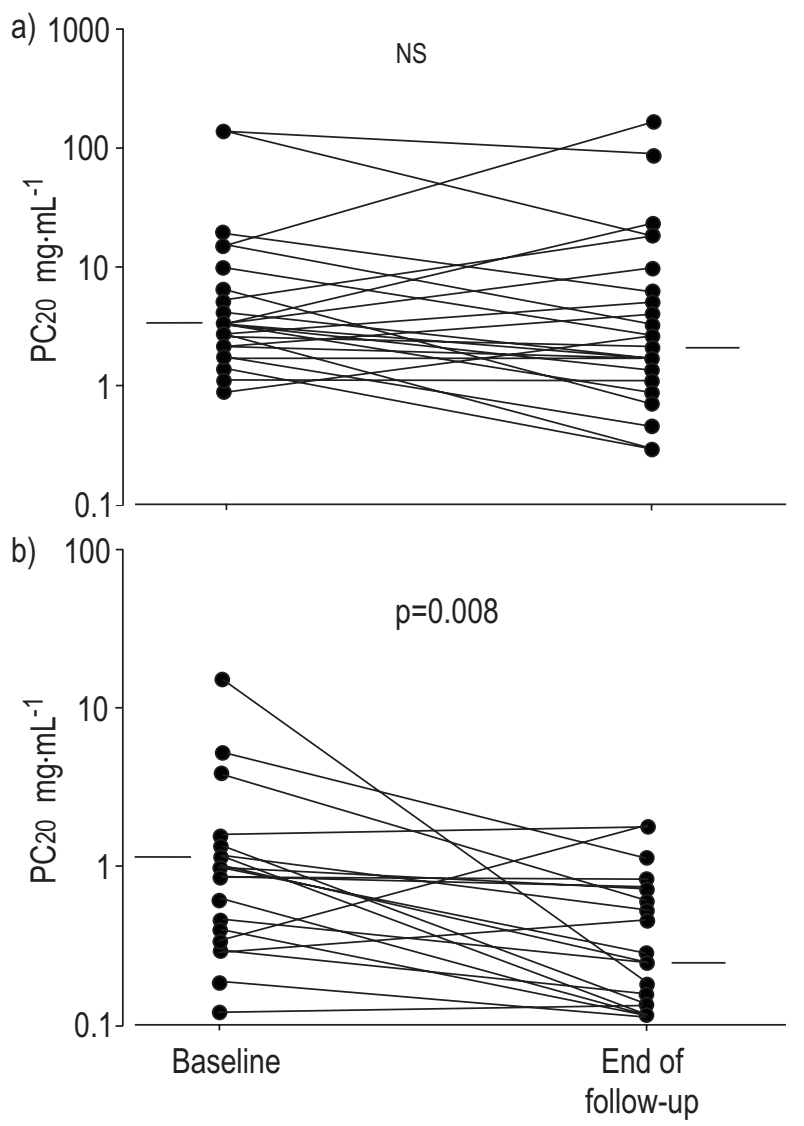

Fig. 5. - Individual values for provocative concentration of methacholine causing a $20 \%$ fall in forced expiratory volume in one second (PC20) in subjects with plateau (a) and without plateau (b) at baseline and at the end of the follow-up period. Horizontal bars represent geometric means.

a plateau on the concentration-response curves to inhaled methacholine may be used as an objective index for safely reducing the corticosteroid dose.

In $24 \%$ (11 of 46 ) of the subjects in the current study, a deterioration of asthma was detected after reduction of inhaled budesonide. Therefore, from these results it is evident that in most patients with moderate asthma, wellcontrolled with budesonide, the dose of this drug can be reduced without clinical deterioration. In contrast, SPENCE et al. [5] reported that after establishing the optimal treatment, the reduction of inhaled steroids produced a relapse of asthma in $78 \%$ of patients, and BiANCO et al. [24] showed that halving the dose of beclomethasone dipropionate caused worsening of asthma in $70 \%$ of the patients after 4 weeks. Furthermore, some studies [25, 26] detected a significant deterioration of asthma control after halving the dose of inhaled steroid in asthmatic patients requiring high doses of inhaled beclomethasone dipropionate or flunisolide for clinical control. Differences in results might be explained in part by differences in duration of inhaled corticosteroid treatment, patient characteristics at baseline and drug-inhaler combinations used. It has been shown that inhalers may differ markedly in output characteristics and drug delivery to the intrapulmonary airways [27]. In agreement with this, it is well known that the Turbuhaler device delivers twice as much drug to the airways and lungs as a metered-dose inhaler [28], and this difference in delivery can alter the apparent efficacy of budesonide [29]. Indeed, in one study [9] of mild asthmatic patients treated for 1 yr with inhaled budesonide, half of the subjects continued the drug for a further 3 months at the end of study, whereas in the remainder budesonide was either continued at half the initial dose or stopped altogether. In the reduction group, five $(35 \%)$ subjects experienced a deterioration in symptoms and a decrease in FEV1. More recently, another study [10] observed that the long-term remission during a 2 -yr treatment period with 1,200 $\mu \mathrm{g}$ of budesonide was maintained for well over $1 \mathrm{yr}$ in patients treated with a dose that was reduced to one-third of the previous dosage. However, four (21\%) patients deteriorated after reduction of inhaled budesonide. These findings are consistent with the present results.

It has been suggested that patients who remained in the moderate-to-severe range of airway responsiveness (PC20 $<2 \mathrm{mg} \cdot \mathrm{mL}^{-1}$ ) after a year receiving regular budesonide were more likely to deteriorate when the medication was reduced [9]. However, in the present study there was no difference in airway sensitivity at baseline (table 4) between subjects who deteriorated after budesonide reduction and those who remained well-controlled. Moreover, the deterioration in the control of asthma after reduction of inhaled budesonide could not easily be predicted from either pulmonary function or previous history. The difference in results might be explained in part by differences in patient characteristics. The overall asthma control in these patients was probably better at study entry than that in the study of JUNIPER et al. [9]. This was undoubtedly due to the current strict inclusion criteria. These different inclusion criteria are reflected in the as-needed $\beta$-agonist consumption at baseline, which was between 0 and 8

Table 4. - Baseline characteristics of subjects who showed deterioration of asthma and those who remained well-controlled after budesonide reduction

\begin{tabular}{lccc}
\hline & Deterioration $(\mathrm{n}=11)$ & Acceptable control $(\mathrm{n}=35)$ & $\mathrm{p}$-value \\
\hline Age yrs & $32.8 \pm 4.1$ & $32.7 \pm 2.1$ & 0.99 \\
Male/female & $3 / 8$ & $12 / 23$ & 0.70 \\
Duration of asthma yrs & $15.9 \pm 3.3$ & $14.7 \pm 1.4$ & 0.72 \\
Duration of treatment months & $14.7 \pm 0.4$ & $16.4 \pm 0.7$ & 0.15 \\
Atopy yes/no & $9 / 2$ & $23 / 12$ & 0.41 \\
FEV1 \% pred & $94.1 \pm 4.1$ & $101.0 \pm 1.9$ & 0.11 \\
PC20 mg.mL $\mathrm{mL}^{-1}$ & $1.6(0.2-9.5)$ & $2.9(0.1-198.0)$ & 0.32 \\
Slope fall in FEV1 (\%)/log methacholine concentration $\left(\mathrm{mg} \cdot \mathrm{mL}^{-1}\right)$ & $23.3 \pm 3.6$ & $23.6 \pm 2.9$ & 0.96 \\
\hline
\end{tabular}

Data are presented as mean \pm SEM unless otherwise stated. PEF: peak expiratory flow; FEV1: forced expiratory volume in one second; PC20: provocative concentration of methacholine causing a $20 \%$ fall in FEV1. *: data are geometric mean and range. 
inhalations per day in the study of JUNIPER et al. [9], but only between 0 and 2 inhalations per week in this study. Furthermore, the mean baseline FEV1 in the patients studied by JUNIPER et al. [9] was $84 \%$ pred, compared to $102 \%$ in the present subjects with a plateau and to $97.5 \%$ in subjects without a plateau. The reason for selecting patients with stable asthma in good control is that this group would most likely be considered for budesonide reduction.

A primary goal of this investigation was to determine a means of identifying those asthmatic subjects whose condition will not deteriorate when treatment with budesonide is reduced. Only $4 \%$ of the subjects with a plateau deteriorated when the budesonide was reduced. Conversely, just under half of the subjects without a plateau deteriorated during the 3-month treatment period with a reduced dose of budesonide. Moreover, a $75 \%$ reduction in inhaled budesonide dosage was possible in the plateau group without subjective or objective loss of asthma control. On the contrary, in the nonplateau group there was a deterioration in symptoms, bronchodilator use, pulmonary function, and airway sensitivity after reduction of inhaled budesonide. Thus, these results suggest that the presence of a plateau on the concentration-response curve to inhaled methacholine predicts stable disease after reducing the steroid dose, but the absence of a plateau does not predict deterioration of asthma in all patients. Previous studies have shown that, when budesonide was stopped, both the airway sensitivity to methacholine $[8,30,31]$ and the maximal degree of airway narrowing $[15,30]$ returned to pretreatment values within weeks. However, the beneficial effect of inhaled budesonide on airway sensitivity remained for 3-12 months when the dose of the drug was reduced $[9,10]$. The results of this study extend those of previous reports $[9,10]$ and demonstrate that, when inhaled budesonide is reduced after 10-18 months of regular use, methacholine responsiveness (sensitivity and shape of the concentration-response curve) did not deteriorate during a 3-month period in subjects with a plateau. On the contrary, there is an increase in airway sensitivity after reduction of inhaled budesonide in subjects without a plateau.

Based on the hypothesis that the only functional characteristic which can limit the degree of airway obstruction in asthmatics is a plateau at mild-to-moderate degrees of airway narrowing, it has been suggested that the asthma therapy should not be limited to decreasing the sensitivity, but also towards restoring the mechanism which protects against excessive bronchoconstriction $[32,33]$. In contrast to other drugs, inhaled steroids not only shift the concentration-response curve to spasmogens to the right, but also limit the maximum narrowing in response to bronchoconstrictor agents $[15,32]$. The present study shows that airway responsiveness is abnormal (absence of a plateau) in half of the asthmatic subjects well-controlled by treatment with inhaled budesonide. These results suggest that the introduction of a plateau on the concentration-response curve to methacholine is not a requirement to achieve an adequate asthma control by treatment with inhaled steroids.

Data on the prevalence of a plateau in asthmatic patients treated with inhaled steroids are scanty. Booms et al. [15] have recently shown that 9 of $14(64 \%)$ subjects, with mild asthma had a plateau after 12 weeks of treatment with budesonide $(1,600 \mu \mathrm{g}$ daily). The differences in design, patient characteristics, challenge methods, dose and duration of treatment between that study and the present study preclude a proper comparison. Furthermore, the definition of a plateau varies among investigators, and some of the disparity in the proportion of subjects exhibiting a plateau may be explained by these differences. A greater prevalence of plateaus would have been seen had FEV1 been allowed to decrease by $60 \%$, as was carried out in the study by Booms et al. [15], rather than setting a $50 \%$ limit.

The present results have clinical implications. Since the clinical significance of unwanted systemic effects of inhaled steroids in the commonly used dose range is currently under debate, titration of the dose of inhaled steroid to the lowest possible long-term level is recommended to minimize the risk of unwanted systemic effects [34]. It seems that in most asthmatic patients, wellcontrolled with a moderately high dose of budesonide, control of the disease can be maintained with a low dose of the drug. Therefore, once control of asthma is sustained for several months, it is justified to consider a reduction in therapy. These results suggest that the analysis of the shape of the concentration-response curve for inhaled methacholine is a means of identifying those asthmatic subjects whose condition will not deteriorate when budesonide is reduced.

Acknowledgements. The authors thank the patients who willingly participated and R. Rojas for her technical assistance. The budesonide and terbutaline inhalers used in the study were provided by Astra, Spain.

\section{References}

1. Global Initiative for Asthma. Global strategy for asthma management and prevention. Publication No. 95-3659, Washington, DC: National Heart, Lung, and Blood Institute, 1995.

2. Kamada AK, Szefler SJ, Martin RJ, et al. Issues in the use of inhaled glucocorticoids. Am J Respir Crit Care Med 1996; 153: 1739-1748.

3. Garbe E, LeLorier J, Boivin JF, Suissa S. Inhaled and nasal glucocorticoids and the risks of ocular hypertension or open-angle glaucoma. JAMA 1997; 272: 722-727.

4. Haahtela T, Järvinen M, Kava T, et al. Comparison of a $\beta_{2}$-agonist, terbutaline, with an inhaled corticosteroid, budesonide, in newly detected asthma. $N$ Engl J Med 1991; 321: 388-392.

5. Spense DPS, Johnston SL, Calverley PMA, et al. The effect of the orally active platelet-activating factor antagonist WEB2086 in the treatment of asthma. Am J Respir Crit Care Med 1994; 149: 1142-1148.

6. Wong CS, Cooper S, Britton JR, Tattersfield AE. Steroid sparing effect of nedocromil sodium in asthmatic patient on high doses of inhaled steroids. Clin Exp Allergy 1993; 23: 370-376.

7. British Thoracic Society. The British Guidelines on Asthma Management. 1995 Review and Position Statement. Thorax 1997; 52 (Suppl. 1): S1-S21.

8. Waalkens HJ, van Essen-Zandvliet EE, Hughes MD, et al. Cessation of long-term treatment with inhaled corticosteroid (budesonide) in children with asthma results in deterioration. Am Rev Respir Dis 1993; 148: 1252-1257. 
9. Juniper EF, Kline PA, Vanzieleghem MA, Hargreave FE. Reduction of budesonide after a year of increased use: a randomized controlled trial to evaluate whether improvements in airway responsiveness and clinical asthma are maintained. J Allergy Clin Immunol 1991; 87: 483-489.

10. Haahtela T, Järvinen M, Kava T, et al. Effects of reducing or discontinuing inhaled budesonide in patients with mild asthma. N Engl J Med 1994; 331: 700-705.

11. Woolcock AJ. What is bronchial hyperresponsiveness from the clinical standpoint? In: Page CP, Gardiner PJ, eds. Airway Hyperresponsiveness: Is it Really Important for Asthma? Oxford, Blackwell Scientific Publications, 1993; pp. 1-9.

12. Woolcock AJ, Salome CM, Yan K. The shape of the doseresponse curve to histamine in asthmatic and normal subjects. Am Rev Respir Dis 1984; 130: 71-75.

13. James A, Luogheed D, Pearce-Pinto G, Ryan G, Musk B. Maximal airway narrowing in a general population. $\mathrm{Am}$ Rev Respir Dis 1992; 146: 895-899.

14. Prieto L, Gutiérrez V, Morales C, Marín J. Differences in sensitivity, maximal response and position of the concentration-response curve to methacholine between asthmatics, patients with allergic rhinitis and healthy subjects. Respir Med 1998; 92: 88-94.

15. Booms $\mathrm{P}$, Cheung D, Timmer MC, Zwinderman AH, Sterk PJ. Protective effect of inhaled budesonide against unlimited airway narrowing to methacholine in atopic patients with asthma. J Allergy Clin Immunol 1997; 99: 330-337.

16. Prieto L, Gutiérrez V, Morales C, Perpiñan J, Inchaurraga I. Variability of peak expiratory flow rate in allergic rhinitis and mild asthma: relationship to maximal airway narrowing. Ann Allergy Asthma Immunol 1998; 80: 151-158.

17. American Thoracic Society. Standards for the diagnosis and care of patients with chronic obstructive pulmonary disease (COPD) and asthma. Am Rev Respir Dis 1987; 136: 225-234.

18. American Thoracic Society. Standardization of spirometry - 1987 update. Am Rev Respir Dis 1987; 136: 1285-1298.

19. Quanjer $\mathrm{PhH}$, ed. Standardized lung function testing. Bull Eur Physiopathol Respir 1983; 19 (Suppl. 15): 1-95.

20. Cockcroft DW, Killian DN, Mellon JJA, Hargreave FE. Bronchial reactivity to inhaled histamine: a method and clinical survey. Clin Allergy 1977; 7: 235-243.

21. Prieto L, Bertó JM, Gutiérrez V, Tornero C. Effect of inhaled budesonide on seasonal changes in sensitivity and maximal response to methacholine in pollen-sensitive asthmatic subjects. Eur Respir J 1994; 7: 1845-1851.
22. Prieto L, Marín J. Methacholine inhalation challenge. Practical consequences of using duplicate spirograms after each concentration. Ann Allergy 1993; 70: 487-490.

23. Sterk PJ, Daniel EF, Zamel N, Hargreave FE. Limited bronchoconstriction to methacholine using partial flowvolume curves in nonasthmatic subjects. Am Rev Respir Dis 1985; 132: 272-277.

24. Bianco S, Vaghi A, Robuschi M, Refini RM, Pieroni MG, Sestini P. Steroid-sparing effect of inhaled lysine acetylsalicylate and furosemide in high-dose beclomethasonedependent asthma. J Allergy Clin Immunol 1995; 95: 937-943.

25. Tamaoki J, Kondo M, Sakai N, et al. Leukotriene antagonist prevents exacerbation of asthma during reduction of high-dose inhaled corticosteroid. Am J Respir Crit Care Med 1997; 155: 1235-1240.

26. ZuWallack RL, Rosen JR, Cohen L, et al. The effectiveness of once-daily dosing of inhaled flunisolide in maintaining asthma control. J Allergy Clin Immunol 1997; 99: 278-285.

27. Pedersen S. Inhalers and nebulizers, which to choose and why. Respir Med 1996; 90: 69-77.

28. Thorsson L, Edsbäcker S, Conradson TB. Lung deposition of budesonide from Turbuhaler is twice that from a pressurized metered-dose inhaler P-MDI. Eur Respir J 1994; 7: 1839-1844.

29. Agertoft L, Pedersen S. Importance of the inhalation device on the effect of budesonide. Arch Dis Child 1993; 69: 130-133.

30. Kraan J, Koëter GH, Mark ThW, Sluiter HJ, de Vries $\mathrm{K}$. Changes in bronchial hyperreactivity induced by 4 weeks of treatment with antiasthmatic drugs in patients with allergic asthma: a comparison between budesonide and terbutaline. J Allergy Clin Immunol 1985; 76: 628636.

31. Vathenen AS, Knox AJ, Wisniewski A, Tattersfield AE. Time course of change in bronchial reactivity with an inhaled corticosteroid in asthma. Am Rev Respir Dis 1991; 143: 1317-1321.

32. Bel EH, Timmers MC, Zwinderman AH, Dijkman JH, Sterk PJ. The effect of inhaled corticosteroids on the maximal degree of airway narrowing to methacholine in asthmatic subjects. Am Rev Respir Dis 1991; 143: 109-113.

33. Macklem PJ. A hypothesis linking bronchial hyperreactivity and airway inflammation: implications for therapy. Ann Allergy 1990; 64: 113-116.

34. Barnes PJ. Inhaled glucocorticoids for asthma. $N$ Engl $J$ Med 1995; 332: 868-875. 